Journal of Pharmaceutical Science and Medical Research

Vol. 3, No.2, Agustus 2020, hal 73 - 84

ISSN (online): 2614-4840 ISSN (cetak): 2614-6118

Avaliable online at: http://e-journal.unipma.ac.id/index.php/pharmed

\title{
Analisis Pengaruh Pengadaan Obat Terhadap Kepuasan Apoteker di FKTP
}

\author{
Ika Andriana ${ }^{1}$, Pulung Prabowo ${ }^{2}$ \\ 1) Universitas PGRI Madiun, Jalan Setia Budi No. 85 Madiun \\ 2)Universitas Katolik Widya Mandala Madiun, Jl. Manggis No.15-17, Kejuron, Kec. \\ Taman, Kota Madiun, Jawa Timur 63131 \\ e-mail: ${ }^{1)}$ andriana@unipma.ac.id; ${ }^{2)}$ pulung.prabowo@gmail.com
}

\begin{abstract}
Abstrak
Kepuasan apoteker berperan penting terhadap tingkat kualitas pelayanan BPJS Kesehatan sebab dengan pelayanan BPJS Kesehatan yang baik maka akan memberikan kepuasan apoteker sebagai penyedia layanan kefarmasian di Fasilitas Kesehatan Tingkat I (FKTP). Tujuan penelitian ini adalah untuk mengetahui pengaruh pengadaan obat terhadap kepuasan apoteker di FKTP Kabupaten Jombang dan Madiun. Penelitian ini dilakukan di FKTP Kabupaten Jombang dan Madiun meliputi puskesmas, klinik pratama, dan apotek jejaring. Metode pengambilan sampel secara total sampling terhadap 21 apoteker yang melakukan pelayanan BPJS Kesehatan di FKTP dengan menggunakan variabel bebas pengadaan obat. Data diperoleh dengan menyebarkan secara langsung kuesioner, kemudian data dianalisis menggunakan regresi linear dengan program komputer spss versi 18. Hasil penelitian dapat disimpulkan bahwa pengadaan obat berpengaruh signifikan terhadap kepuasan apoteker dengan nilai signifikan 0.00 .
\end{abstract}

Kata kunci: Pengadaan, Kepuasan, Apoteker, FKTP, BPJS

\section{Influence Analysis Of The Drug Procurement On Pharmacys Satisfaction in First Level Health Facilities}

\begin{abstract}
Pharmacist satisfaction could be an important role toward the service level quality of BPJS Kesehatan. It is because, a good service of BPJS Kesehatan will give a pharmacist satisfaction as the provider of pharmaceutical service in the first grade of health facility. The aim of the study is to determine what the drug procurement toward the pharmacist satisfaction in first grade of health facility of Jombang and Madiun district. This study had been done in first level health facilities of Jombang and Madiun district including health center, pratama clinic, and drugstore networks. The method in taking sampling had been done by taking 21 pharmacists that were doing BPJS Kesehatan service in first level health facilities. The method was done by using independent variable drug procurement, distribution of drugs, and drug claims. The data were obtained by distributing questionnaires directly. Then the data were analyzed using linear regression with a computer program spss 18 version. It can be concluded that the procurement of drugs significantly influenced the pharmacist satisfaction with the significant value 0,00 .
\end{abstract}

Keywords: Procurement, Satisfaction, Pharmacist, FKTP, BPJS 


\section{Pendahuluan}

Penetapan Undang-Undang Nomor 40 Tahun 2004 tentang Sistem Jaminan Sosial Nasional (SJSN) telah membantu mewujudkan bangsa Indonesia untuk memiliki Sistem Jaminan Sosial bagi seluruh rakyat Indonesia. Untuk mewujudkan tujuan SJSN perlu dibentuk badan penyelenggara yang berbentuk badan hukum publik berdasarkan prinsip kegotongroyongan, nirlaba, keterbukaan, kehati-hatian, akuntabilitas, portabilitas, kepesertaan bersifat wajib, dana amanat, dan hasil pengelolaan dana jaminan sosial dipergunakan seluruhnya untuk pengembangan program dan untuk sebesar-besarnya kepentingan peserta. (Pemerintah RI, 2004)

Dalam pelaksanaannya, program BPJS melibatkan seluruh komponen kesehatan, agar taraf hidup kesehatan masyarakat meningkat. Tugas apoteker adalah melakukan praktik kefarmasian yang meliputi pembuatan, termasuk pengendalian untuk sediaan farmasi, pengamanan, pengadaan penyimpanan dan pendistribusian, pelayanan obat atas resep dokter, pelayanan informasi obat serta pengembangan obat, bahan obat dan obat tradisional. Peraturan Pemerintah Nomor 51 Tahun 2009 tentang Pekerjaan Kefarmasian dengan jelas telah mengatur fungsi dan peranan apoteker dalam dunia kesehatan. Obat dan perbekalan kesehatan merupakan komponen yang tak tergantikan dalam pelayanan kesehatan. Akses terhadap obat terutama obat esensial merupakan salah satu hak azasi manusia. Dengan demikian penyediaan obat esensial merupakan kewajiban bagi pemerintah dan lembaga pelayanan kesehatan baik publik maupun swasta. (Menteri kesehatan RI, 2008)

Cakupan pelayanan obat oleh BPJS kepada peserta meliputi pemberian obat pada rawat jalan tingkat pertama (RJTP) atau rawat inap tingkat pertama di fasilitas kesehatan tingkat primer (FKTP), dan pemberian obat rawat jalan tingkat lanjutan (RJTL), atau rawat inap di fasilitas kesehatan tingkat lanjut (FKTL). Daftar dan harga obat serta bahan medis habis pakai (BMHP) mengacu pada ketentuan yang ditetapkan Kepmenkes. Untuk daftar obat dan BMHP acuannya adalah formularium nasional (Fornas) dan harganya merujuk kepada e-catalogue. Namun e-catalogue tahun 2014 belum seluruhnya digunakan oleh FKTP. (Menteri kesehatan RI, 2008)

Berdasarkan Peraturan Presiden Nomor 54 Tahun 2010 tentang Pengadaan Barang/Jasa Pemerintah sebagaimana telah diubah terakhir dengan Peraturan Presiden Nomor 70 Tahun 2012, pengadaan obat harus dilaksanakan berdasarkan prinsip penyelenggaraan pemerintah yang baik dan bersih, prinsip keadilan, transparansi, profesional, dan akuntabel untuk mendapatkan produk yang berkualitas dengan harga yang wajar baik untuk program Jaminan Kesehatan Nasional maupun program kesehatan lainnya. Untuk mempermudah pengadaan obat, Lembaga Kebijakan Pengadaan Barang/Jasa Pemerintah (LKPP) telah menetapkan Katalog Elektronik ( $E$-Catalogue) Obat yang berisi daftar harga, spesifikasi dan penyedia obat. Katalog Elektronik ( $E$-Catalogue) adalah sistem informasi elektronik yang memuat daftar, jenis, spesifikasi teknis, dan harga barang tertentu dari berbagai Penyedia Barang/Jasa Pemerintah. Hal ini untuk menjamin ketersediaan dan pemerataan obat yang aman, bermutu, dan berkhasiat untuk memenuhi kebutuhan pelayanan kesehatan, perlu dilaksanakan pengadaan obat secara transparan, efektif, efisien serta hasilnya dapat dipertanggungjawabkan. Pengadaan obat dilaksanakan berdasarkan $e-$ Catalogue dengan menggunakan metode pembelian secara elektronik (e-Purchasing) sebagaimana tercantum dalam e-Catalogue yang ditetapkan oleh Kepala LKPP. (Menteri kesehatan RI, 2014)

Terdapat beberapa keluhan yang diungkapkan oleh penyedia layanan FKTP di Kabupaten Jombang dan Madiun diantaranya yang pertama adalah pelaksanaan sistem e-catalogue. Pengadaan obat dengan sistem e-catalogue di Puskesmas yang belum BLUD (Badan Layanan Umum Daerah) masih menggunakan pengadaan obat kepada Gudang Farmasi Dinas Kesehatan setempat. Secara kualitas dan kuantitas 
obat sudah baik dengan memiliki masa kadaluarsa yang panjang namun yang menjadi kendala adalah obat datang terlalu lama sehingga sering terjadi kekosongan obat dan berdampak pada pembatasan pemberian obat kepada pasien.

Kegiatan pengadaan obat di Puskesmas mencakup penyusunan dan pengajuan permintaan obat kepada Gudang Farmasi sesuai dengan kebutuhan. Pengadaan dilakukan sebagai bentuk realisasi dari perencanaan kebutuhan yang telah dilakukan oleh Puskesmas. Efektivitas kegiatan pengadaan ditunjukkan melalui ketersediaan obat, kesesuaian jumlah obat dengan kebutuhan, kesesuaian harga obat (Hadidah, 2016). Namun, Puskesmas tidak bisa melakukan pengadaan obat secara mandiri. Terdapat perubahan sistem pengadaan untuk obat Jaminan Kesehatan Nasional sejak diberlakukannya Badan Penyelenggara Jaminan Sosial awal tahun 2014, yaitu Puskesmas boleh membeli obat menggunakan uang kapitasi yang diperoleh dari pembayaran kapitasi Badan Penyelenggara Jaminan Sosial Kesehatan kepada Puskesmas setiap bulannya, pelaksanaannya terealisasi pertengahan tahun 2014. (Rosmania, 2015)

Implementasi pengadaan obat dan bahan medis habis pakai di puskesmas masih terdapat beberapa kendala diantaranya yaitu kegiatan pengadaan yang membutuhkan waktu yang lama, Puskesmas tidak bisa melakukan pengadaan di luar periode pengadaan obat dan bahan medis habis pakai, dan kurangnya pemantauan Dinas Kesehatan Kota terhadap distributor obat. (Rahmah, 2018). Sejauh ini diperlukan pengembangan dan evaluasi mengenai sistem yang dijalankan BPJS di sektor fasilitas pelayanan kesehatan khususnya pada tingkat pertama. Dengan demikian diperlukan kerjasama yang baik antara pemerintah, BPJS dan tenaga kesehatan di fasilitas kesehatan guna mendukung berjalannya program Jaminan Kesehatan Nasional (JKN) dengan baik. Adanya realitas tersebut mendorong dilakukannya penelitian untuk melakukan penilaian kepuasan apoteker mengenai pengadaan obat sebagai bahan evaluasi terhadap pelayanan BPJS guna memaksimalkan pelayanan kesehatan di FKTP.

\section{Metode Penelitian}

Penelitian ini merupakan penelitian asosiatif yang merupakan penelitian untuk mengetahui hubungan antara dua variabel atau lebih. Dengan penelitian ini maka akan dapat dibangun suatu teori yang dapat berfungsi untuk menjelaskan, meramalkan dan mengkontrol suatu gejala dengan adanya hubungan sebab akibat (Sugiyono, 2004). Penelitian ini dilakukan mulai tanggal 1 Desember 2014 sampai dengan 15 Januari 2015. Data diperoleh dari survei, dengan cara membagikan kuesioner kepada responden (Apoteker) yang memuat sejumlah pertanyaan yang harus dijawab oleh responden di FKTP Kabupaten Jombang dan Madiun. Data yang diperoleh kemudian dilakukan analisis regresi linier menggunakan komputer.

Populasi dalam penelitian ini adalah seluruh Apoteker yang bekerja di FKTP Kabupaten Jombang dan Madiun. Sampel dalam penelitian ini adalah seluruh Apoteker yang melayani pasien BPJS di FKTP Kabupaten Jombang dan Madiun. Apoteker yang dijadikan sampel harus memenuhi kriteria inklusi yang meliputi :

1. Apoteker yang melakukan pelayanan BPJS Kesehatan di Puskesmas.

2. Apoteker yang melakukan pelayanan BPJS Kesehatan di Klinik Pratama.

3. Apoteker yang melakukan pelayanan BPJS Kesehatan di Apotek jejaring.

Teknik pengambilan sampel yang digunakan dalam penelitian ini adalah total sampling yaitu teknik penentuan sampel dengan mengambil seluruh anggota populasi sebagai responden atau sampel. (Sugiono, 2009) Apoteker adalah karakteristik subyek yang ditetapkan sebagai kriteria populasi yang sudah melakukan pelayanan BPJS Kesehatan di FKTP. Saat ini terdapat 74 (tujuh puluh empat) FKTP di Kabupaten Jombang dan Madiun yang bekerja sama dengan BPJS Kesehatan. Namun tidak 
seluruhnya terdapat apoteker sehingga dapat dikatakan bahwa seluruh apoteker yang berada di FKTP digunakan sebagai sampel penelitian (total sampling).

Tabel 1. Data FKTP di Kabupaten Jombang dan Madiun

\begin{tabular}{clc} 
Kabupaten/Kota & \multicolumn{1}{c}{ FKTP } & Jumlah \\
\hline Madiun & Puskesmas & 17 \\
\hline & Apotek jejaring & 5 \\
\hline & Klinik pratama & 5 \\
\hline Jombang & Puskesmas & 34 \\
\hline & Apotek jejaring & 2 \\
\hline & Klinik pratama & 11 \\
\hline Jumlah & 74 \\
\hline
\end{tabular}

Kuesioner (questionnaire) merupakan suatu bentuk instrumen pengumpulan data yang sangat flexibel dan relatif mudah digunakan. Mengukur varibel pengadaan obat menggunakan skala Likert. Skala Likert adalah skala yang memuat tentang pernyataan respon jawaban menunjukkan tingkat persetujuan atau ketidaksetujuan. Jawaban setiap item instrumen yang menggunakan skala Likert mempunyai gradiasi dari sangat positif sampai sangat negatif.

Tabel 2. Pengukuran skala Likert dan poin dari pernyataan

\begin{tabular}{lcc}
\hline \multirow{2}{*}{ Format skala Likert } & \multicolumn{2}{c}{ Pernyataan } \\
\cline { 2 - 3 } & Favourable & Unfavourable \\
\hline Sangat setuju & 4 & 1 \\
\hline Setuju & 3 & 2 \\
\hline Tidak setuju & 2 & 3 \\
\hline Sangat tidak setuju & 1 & 4 \\
\hline
\end{tabular}

Pengukuran variabel-variabel didasarkan pada indikator variabel yang secara lengkap dapat dijelaskan dalam tabel berikut:

Tabel 3. Variabel-Variabel dan Indikator Kuesioner Penelitian

\begin{tabular}{ccc}
\hline Variabel & Tolok ukur & Skala \\
\hline X1: & e-catalogue dan Formularium & Skala Likert \\
nengadional & & \\
\hline Y : & Kepuasan terhadap pelayanan & Skala Likert \\
Kepuasan Apoteker & BPJS Kesehatan kepada FKTP & \\
\hline Sumber : (Menteri Kesehatan RI, 2014) &
\end{tabular}

\section{Hasil dan Pembahasan}

Klinik dalam menyelenggarakan pengelolaan dan pelayanan kefarmasian melalui ruang farmasi yang dilaksanakan oleh apoteker yang sesuai dengan kompetensi dan kewenangan. (Menteri kesehatan RI, 2011). Namun pada kenyataannya di Kabupaten Jombang dan Madiun masih banyak klinik yang belum memiliki apoteker karena beberapa faktor diantaranya keterbatasan apoteker di daerah tersebut. Hal inilah yang menyebabkan adanya keterbatasan responden dalam penelitian. 
Tabel 4. Daftar FKTP yang Terdapat Apoteker Kab.Jombang dan Madiun tahun 2014

\begin{tabular}{clcc}
\hline Kabupaten/kota & \multicolumn{1}{c}{ FKTP } & Jumlah & Apoteker \\
\hline Madiun & Puskesmas & 17 & 6 \\
\hline & Apotek jejaring & 5 & 5 \\
\hline & Klinik pratama & 5 & 0 \\
\hline Jombang & Puskesmas & 34 & 5 \\
\hline & Apotek jejaring & 2 & 2 \\
\hline & Klinik pratama & 11 & 3 \\
\hline & Jumlah & 74 & 21
\end{tabular}

Pada tabel 4 diketahui bahwa FKTP khususnya Puskesmas dan Klinik pratama di Kabupaten Jombang dan Madiun masih belum memiliki Apoteker. Sejauh ini pelayanan kefarmasian masih dilakukan oleh Tenaga Teknis Kefarmasian. Pentingnya peran Apoteker dalam pelayanan kesehatan khususnya dalam bidang kefarmasian mengharuskan Apoteker untuk melakukan praktik kefarmasian di fasilitas kesehatan. Dalam hal ini pemerintah Dinas Kesehatan dan Organisasi profesi setempat sebaiknya memberikan himbauan dan sanksi tegas terhadap fasilitas pelayanan kesehatan yang belum memiliki Apoteker karena sudah tidak sesuai dengan Permenkes di atas.

Tenaga kefarmasian berperan penting dalam ketersediaan obat yaitu salah satu faktor dalam hal pengadaan obat Salah satu faktor yang dapat menjamin ketersediaan obat yang bermutu dapat dipantau melalui proses pengadaan obat. Manajemen pendukung dalam proses pengadaan obat meliputi SDM, organisasi, sarana/fasilitas dan Sistem Informasi Manajemen serta anggaran sudah sesuai dengan peraturan pengadaan obat yang berlaku. Proses pengadaan obat ditinjau dari waktu, frekuensi, dan kesesuaian dengan perencanaan sudah sesuai dengan teori dan peraturan pengadaan obat. (Prabowo, 2016)

\section{A. Uji Instrumen}

\section{Uji Validitas}

Teknik pengujian validitas menggunakan program SPSS version 18 dihasilkan analisis nilai Corrected Item-Total Correlation r- hitung > r- tabel, maka item pernyataan tersebut dikatakan valid, tetapi jika $r$-hitung $<r$ - tabel maka item pernyataan tersebut tidak valid. Nilai r-tabel untuk uji satu sisi pada taraf kepercayaan $95 \%$ atau signifikan $5 \%(\mathrm{p}$ value $=0,05)$. Dalam penelitian ini jumlah sampel adalah $\mathrm{n}=21$, maka derajat bebasnya (df) adalah $n-2=21-2=19$. Diketahui pada nilai $r$ - tabel $d f=19$ dengan $p$ value $=0,05$ adalah 0,2914 . Hasil analisis uji validitas dari item-item pernyataan kuesioner adalah sebagai berikut:

\subsection{Variabel bebas Pengadaan obat $\left(\mathrm{X}_{1}\right)$}

Berdasarkan tabel 5 menunjukkan bahwa ada 1 item pernyataan yang memiliki nilai $r$-hitung $<$ r-tabel 0,2914 dan 10 item pernyataan yang memiliki $r$-hitung $>r$-tabel dengan demikian 10 item pernyataan tersebut valid dan dapat digunakan untuk menguji sampel penelitian. Pernyataan yang tidak valid dengan hasil $r$ - hitung 0,139 yaitu pernyataan 2 "sistem e-catalogue sudah disiapkan oleh BPJS dan mudah dioperasikan oleh apoteker". Item pernyataan tersebut tidak valid karena terdapat perbedaan pendapat oleh apoteker yang bekerja di Puskesmas dengan apoteker yang bekerja di apotek jejaring/rujuk balik. Sehingga item pernyataan tersebut tidak digunakan sebagai alat ukur dalam penelitian ini. 
Tabel 5. Hasil uji validitas variabel bebas pengadaan obat $\left(X_{1}\right)$

\begin{tabular}{lcccc}
\hline Variabel & $\begin{array}{c}\text { Item } \\
\text { pernyataan }\end{array}$ & $\begin{array}{c}\text { r-hitung } \\
\text { (Corrected item- } \\
\text { total correlation) }\end{array}$ & r-tabel & Keterangan \\
\hline Pengadaan & Pernyataan 1 & 0,679 & & Valid \\
obat & Pernyataan 2 & $0,139^{*}$ & Tidak Valid \\
& Pernyataan 3 & 0,693 & Valid \\
& Pernyataan 4 & 0,800 & 0,2914 & Valid \\
& Pernyataan 5 & 0,646 & & Valid \\
& Pernyataan 6 & 0,693 & & Valid \\
& Pernyataan 7 & 0,763 & Valid \\
& Pernyataan 8 & 0,797 & Valid \\
& Pernyataan 9 & 0,675 & Valid \\
& Pernyataan 10 & 0,764 & Valid \\
& Pernyataan 11 & 0,734 & Valid \\
\hline
\end{tabular}

Sumber: data primer yang diolah, 2015

Apoteker puskesmas mengalami kemudahan dalam pengoperasian ecatalogue sebagai pedoman pengadaan ke Gudang Farmasi Kota (GFK) Dinas Kesehatan setempat. Hal ini dikarenakan BPJS sudah melakukan sosialisasi penggunaan e-catalogue untuk instansi kesehatan milik daerah. Sedangkan apoteker di apotek jejaring belum melakukan pengadaan berdasarkan e-catalogue karena BPJS di Kabupaten Jombang dan Madiun saat ini belum menjalankan system tersebut untuk apotek jejaring/rujuk balik. Sehingga pengadaan obat masih manual dan apoteker belum begitu memahami sistem e-catalogue tersebut.

\subsection{Variabel tergantung Kepuasan Apoteker (Y)}

Tabel 1. Hasil uji validitas variabel tergantung kepuasan apoteker (Y)

\begin{tabular}{ccccc}
\hline Variabel & $\begin{array}{c}\text { Item } \\
\text { pernyataan }\end{array}$ & $\begin{array}{c}\text { r-hitung } \\
\text { (Corrected } \\
\text { item-total } \\
\text { correlation) }\end{array}$ & r-tabel & Keterangan \\
\hline Kepuasan & Pernyataan 1 & 0,579 & & \\
Apoteker & Pernyataan 2 & 0,579 & Valid \\
& Pernyataan 3 & $0,163^{*}$ & & Valid \\
& Pernyataan 4 & 0,636 & \multirow{2}{*}{0,2914} & Valid \\
& Pernyataan 5 & 0,484 & Valid \\
& Pernyataan 6 & 0,502 & & Valid \\
& Pernyataan 7 & 0,591 & Valid \\
& Pernyataan 8 & $0,132^{*}$ & & Tidak Valid \\
\hline
\end{tabular}

Sumber: data primer yang diolah, 2015

Berdasarkan tabel 6 menunjukan bahwa ada 2 item pernyataan yang memiliki nilai $r$-hitung $<$ r-tabel 0,2914 dan 6 item pernyataan yang memiliki $r$-hitung $>r$-tabel dengan demikian 6 item pernyataan tersebut valid dan dapat digunakan untuk menguji sampel penelitian. Pernyataan yang tidak valid dengan hasil $r$-hitung 0,163 yaitu pernyataan " apoteker di FKTP puas/senang bekerjasama dengan BPJS. Dalam pernyataan tersebut terdapat perbedaan pendapat antara para apoteker di FKTP mengenai kepuasan bekerjasama dengan BPJS karena hal ini berhubungan dengan pendapat pribadi sesuai pelayanan BPJS secara keseluruhan di FKTP. Apoteker di puskesmas sebagian besar tidak setuju karena sistem BPJS yang semakin rumit dan banyak menambah pekerjaan apoteker dalam pelayanan kefarmasian. Terdapat pula 
perubahan kebijakan yang kurang sosialisasi sehingga apoteker kurang memahami. Sedangkan apoteker di apotek jejaring sebagian besar puas dalam bekerjasama dengan BPJS karena sejauh ini masih berjalan dengan baik.

\section{Uji Reliabilitas}

Reliabilitas alat penilaian adalah ketepatan atau keajegan alat tersebut dalam menilai apa yang dinilainya. (Sudjana, 2004) Artinya, kapanpun alat penilaian tersebut digunakan akan memberikan hasil yang relatif sama. Metode yang digunakan dalam pengujian ini adalah metode Cronbach's Alpha, yaitu suatu metode yang apabila nilai Cronbach's Alpha alat ukur di atas 0,6 maka alat ukur yang digunakan tersebut dikatakan reliabel, dan apabila nilai Cronbach's Alpha dibawah 0,6 maka alat ukur yang digunakan tersebut tidak reliabe. (Priyatno, 2010) Hasil analisis dari uji reliabilitas adalah sebagai berikut:

Tabel 2. Hasil uji reliabilitas

\begin{tabular}{lcccl}
\hline \multicolumn{1}{c}{ Variabel } & $\begin{array}{c}\text { N (jumlah) } \\
\text { Item }\end{array}$ & $\begin{array}{c}\text { Koefisien } \\
\text { Cronbach's } \\
\text { Alpha }\end{array}$ & $\begin{array}{c}\text { Cronbach's } \\
\text { Alpha }\end{array}$ & Keterangan \\
\hline $\begin{array}{l}\text { Pengadaan obat } \\
\text { Kepuasan }\end{array}$ & 10 & 0,934 & & Reliabel \\
Apoteker & 6 & 0,881 & 0.6 & Reliabel \\
\hline
\end{tabular}

Sumber: data primer yang diolah, 2015

Berdasarkan tabel 7 dapat dilihat bahwa item pernyataan pada variabel bebas dan variabel tergantung dinyatakan reliabel karena semua variabel memiliki nilai Cronbach `s Alpha lebih besar dari 0,6 dengan demikian item peryataan tersebut dapat digunakan sebagai alat ukur pengujian sampel penelitian.

\section{B. Hasil Pengujian Deskriptif}

\section{Deskripsi Karakteristik Responden}

Karakteristik responden dalam penelitian ini meliputi data pribadi responden yaitu jenis kelamin, usia, dan lama bekerja di FKTP. Karakteristik responden dapat diuraikan sebagai berikut:

Tabel 3. Karakteristik Apoteker di FKTP Kab. Jombang dan Madiun

\begin{tabular}{ccc} 
Karakteristik responden & Frekuensi & Persentase (\%) \\
\hline Jenis kelamin & 2 & \\
Laki-laki & 19 & 9,5 \\
Perempuan & 21 & 100,00 \\
\hline Total & & \\
\hline Usia responden (tahun) & 7 & 33,3 \\
$21-30$ & 11 & 52,4 \\
$31-40$ & 2 & 9,5 \\
$41-50$ & 1 & 4,8 \\
$>50$ & 21 & 100,00
\end{tabular}




\begin{tabular}{ccc} 
Lama kerja (tahun) & & \\
$<1$ & 1 & 4,8 \\
$1-3$ & 7 & 33,3 \\
$3-5$ & 10 & 47,6 \\
$>5$ & 3 & 14,3 \\
\hline Total & 21 & 100,00 \\
\hline Sumber: data primer yang diolah, 2015 & &
\end{tabular}

Sumber: data primer yang diolah, 2015

Pada bagian ini, dijelaskan hasil penelitian dan pada saat yang sama diberikan pembahasan yang komprehensif. Hasil dapat disajikan dalam angka, grafik, tabel dan lain-lain yang membuat pembaca memahami dengan mudah. Pembahasan dapat dibuat dalam beberapa sub-bab sesuai kebutuhan.

\section{Analisis Distribusi Frekuensi dan Distribusi Skor Responden}

Penelitian ini menggunakan 31 item pernyataan alat ukur yang ada dalam variabel bebas dan variabel tergantung. Dalam pernyataan kuesioner terdapat pernyataan yang bersifat favourable (positif) dan pernyataan yang bersifat unfavourable (negative) dengan menggunakan 4 pilihan jawaban yaitu sangat setuju (SS), setuju (S), tidak setuju (TS), dan sangat tidak setuju (STS) dimana jawaban dari kuesioner dianalisis menggunakan metode Likert, dengan melakukan penilaian terhadap masing- masing jawaban dengan skala 1 sampai dengan 4.

Analisis distribusi skor digunakan untuk mengetahui sejauh mana pengaruh variabel bebas pengadaan obat, distribusi obat dan klaim obat terhadap variabel tergantung kepuasan apoteker di FKTP Kabupaten Jombang dan Madiun. Range skor untuk materi-materi pada penilaian 1-5 adalah sebagai berikut. (Abdurrahman, 2003)

\begin{tabular}{cc} 
Tabel 4. Klasifikasi Nilai Kesenjangan \\
\hline Interval & Klasifikasi Jawaban \\
\hline $4,4-4,0$ & Sangat baik \\
\hline $2,8-3,4$ & Baik \\
\hline $2,2-2,8$ & Sedang/ cukup \\
\hline $1,6-2,2$ & Buruk \\
\hline $1-1,6$ & Sangat buruk \\
\hline
\end{tabular}

Skor tertinggi $=4$

Skor terendah $=1$

Distribusi skor $=\frac{\frac{4-1}{5}}{=0,6}$

Responden memberikan banyak jawaban yang bervariasi dalam menjawab item-item pertanyaan yang ada didalam kuesioner. Hasil frekuensi jawaban responden dan distribusi skor terhadap pengadaan obat BPJS Kesehatan di FKTP adalah sebagai berikut :

\subsection{Variabel bebas pengadaan obat $\left(X_{1}\right)$}

Berdasarkan tabel 10 terlihat bahwa jawaban responden terhadap kuisioner pengadaan obat BPJS Kesehatan di FKTP Kabupaten Jombang dan Madiun termasuk dalam kategori sedang/cukup dengan nilai standar deviasi tidak ada yang melebihi dua kali nilai rata-rata. Sebagian besar apoteker di klinik pratama, apotek jejaring atau apotek program rujuk balik masih merasa belum puas dengan pelaksanaan secara teknis pengadaan obat secara $e$ - purchasing dan $e$ - catalogue dikarenakan belum 
adanya sosialisasi penggunaan e- catalogue dan juga program tersebut belum berlaku secara menyeluruh di FKTP. Sehingga apoteker di apotek jejaring dan klinik pratama masih melakukan pengadaan secara manual kepada distributor. Untuk apoteker di puskesmas sudah dapat mengakses e- catalogue pengadaan obat kepada Gudang Farmasi Kesehatan Daerah Dinas Kesehatan setempat.

Tabel 5. Tabel frekuensi dan distribusi skor apoteker terhadap pengadaan obat BPJS Kesehatan di FKTP Kab. Jombang dan Madiun

\begin{tabular}{|c|c|c|c|c|c|c|c|}
\hline \multirow[t]{2}{*}{ Pernyataan Pengadaan Obat } & \multicolumn{4}{|c|}{$\begin{array}{l}\text { Jawaban } \\
\text { responden }\end{array}$} & \multirow{2}{*}{$\begin{array}{l}\text { Skor } \\
\text { total }\end{array}$} & \multirow{2}{*}{$\begin{array}{l}\text { Rata- } \\
\text { rata }\end{array}$} & \multirow{2}{*}{$\begin{array}{l}\text { Standar } \\
\text { Deviasi }\end{array}$} \\
\hline & 1 & 2 & 3 & 4 & & & \\
\hline $\begin{array}{l}\text { 1. Fornas sebagai acuan } \\
\text { pengadaan }\end{array}$ & 0 & 0 & 8 & 13 & 76 & 3,62 & ,498 \\
\hline 2. Obat selalu tersedia & 12 & 9 & 0 & 0 & 30 & 1,67 & ,483 \\
\hline $\begin{array}{l}\text { 3. Pasien tidak mendapat } \\
\text { obat }\end{array}$ & 0 & 0 & 7 & 14 & 77 & 1,62 & ,498 \\
\hline $\begin{array}{l}\text { 4. Terdapat alternatif obat } \\
\text { lain }\end{array}$ & 0 & 0 & 7 & 14 & 77 & 3,57 &, 507 \\
\hline $\begin{array}{l}\text { 5. Usulan fornas } \\
\text { ditindaklanjuti }\end{array}$ & 16 & 5 & 0 & 0 & 26 & 1,67 & ,483 \\
\hline $\begin{array}{l}\text { 6. Informasi sesuai } \\
\text { kebutuhan obat }\end{array}$ & 3 & 18 & 0 & 0 & 39 & 1,76 & ,436 \\
\hline 7. Pengadaan efisien & 3 & 18 & 0 & 0 & 39 & 1,76 & ,436 \\
\hline 8. Pengadaan transparan & 0 & 0 & 15 & 6 & 69 & 3,57 &, 507 \\
\hline 9. Pekerjaan apoteker ringan & 0 & 0 & 6 & 15 & 78 & 3,57 &, 507 \\
\hline \multirow[t]{4}{*}{$\begin{array}{l}\text { 10. Informasi sesuai } \\
\text { pengadaan }\end{array}$} & 0 & 0 & 7 & 14 & 77 & 3,57 &, 507 \\
\hline & & & & & Total & 26,38 & 4,862 \\
\hline & & & & & $\begin{array}{l}\text { Rata- } \\
\text { rata }\end{array}$ & 2,638 & 0,4862 \\
\hline & & & & & Kategori & $\begin{array}{l}\text { Sedang/ } \\
\text { cukup }\end{array}$ & \\
\hline
\end{tabular}

Sumber: data primer yang diolah, 2015

Sebagian besar apoteker menilai sedang / cukup untuk pelayanan BPJS dalam hal pengadaan obat di FKTP Kabupaten Jombang dan Madiun. Hal ini sesuai dengan pernyataan apoteker yang setuju dengan adanya pedoman fornas dan sistem e- catalogue dimana dapat meningkatkan transparansi pengadaan obat, namun masih ada beberapa kekurangan seperti kelengkapan informasi fornas, menambah beban kerja, dan belum meratanya pemakaian sistem e-catalogue di FKTP.

Perhitungan jumlah dan persentase jawaban responden terhadap pernyataan variabel bebas pengadaan obat, dapat diketahui sebagai berikut:

a. Item pernyataan pengadaan obat 7 , diperoleh jumlah dan persentase jawaban dari 21 responden yang telah mengisi kuesioner adalah sebanyak 18 (85,71\%) responden yang menyatakan tidak setuju dan sebanyak $3(14,29 \%)$ responden yang menyatakan sangat tidak setuju. Hal ini berarti apoteker di FKTP Kabupaten Jombang dan Madiun sebagian besar tidak setuju bahwa Fornas dan e-catalogue membuat pengadaan lebih efisien. Pernyataan ini sesuai dengan keterangan apoteker di FKTP puskesmas bahwa sistem e-catalogue belum banyak dipahami dan terkadang terdapat perubahan sebelum disosialisasikan sehingga menambah 
beban kerja apoteker. Sedangkan untuk apoteker di apotek jejaring dan klinik pratama belum memakai sistem e-catalogue sehingga belum mengetahui secara jelas sistem tersebut. Hal tersebut disimpulkan bahwa BPJS Kesehatan belum serentak dalam penggunaan e-catalogue sebagai sistem pengadaan obat.

b. Item pernyataan pengadaan obat 8 , diperoleh jumlah dan persentase jawaban dari 21 responden yang telah mengisi kuesioner adalah sebanyak 15 (71,43\%) responden yang menyatakan setuju dan sebanyak $6(28,57 \%)$ responden yang menyatakan sangat setuju. Apoteker di FKTP Kabupaten Jombang dan Madiun sebagian besar setuju bahwa Fornas dan e-catalogue dapat meningkatkan transparansi dalam pengadaan obat. Pengadaan obat di FKTP berdasarkan $e$ catalogue dimana dalam sistem tersebut terdapat nama sediaan, harga dan distributor yang sudah bekerja sama dengan BPJS, sehingga hal ini dapat menurunkan biaya perbekalan farmasi yang disebabkan oleh promosi, bonus ataupun gratifikasi yang dapat menambah biaya harga obat. Sehingga sistem ini oleh apoteker dinilai dapat meningkatkan transparansi pengadaan perbekalan farmasi.

\subsection{Variabel tergantung kepuasan apoteker $(Y)$}

Tabel 11. Frekuensi dan distribusi skor kepuasan apoteker terhadap pelayanan BPJS Kesehatan di FKTP

\begin{tabular}{|c|c|c|c|c|c|c|c|}
\hline \multirow{2}{*}{$\begin{array}{c}\text { Pernyataan kepuasan } \\
\text { apoteker }\end{array}$} & \multicolumn{4}{|c|}{$\begin{array}{l}\text { Jawaban } \\
\text { responden }\end{array}$} & \multirow{2}{*}{$\begin{array}{l}\text { Skor } \\
\text { total }\end{array}$} & \multirow[t]{2}{*}{ Mean } & \multirow[t]{2}{*}{$\begin{array}{l}\text { Standar } \\
\text { deviasi }\end{array}$} \\
\hline & 1 & 2 & 3 & 4 & & & \\
\hline $\begin{array}{l}\text { 1.Pelayanan BPJS belum } \\
\text { memuaskan }\end{array}$ & 3 & 18 & 0 & 0 & 39 & 1,81 & ,402 \\
\hline $\begin{array}{l}\text { 2.Mendorong apoteker } \\
\text { bekerjasama }\end{array}$ & 0 & 0 & 7 & 14 & 77 & 3,81 & ,402 \\
\hline 3.Apoteker senang bekerjasama & 0 & 0 & 8 & 13 & 76 & 3,52 & ,512 \\
\hline $\begin{array}{l}\text { 4.Pelayanan BPJS berjalan } \\
\text { lancar }\end{array}$ & 0 & 0 & 7 & 14 & 77 & 3,52 & ,512 \\
\hline 5.Keluhan ditindaklanjuti & 12 & 9 & 0 & 0 & 30 & 1,62 & ,498 \\
\hline $\begin{array}{l}\text { 6.Apoteker mempertahankan } \\
\text { kerjasama }\end{array}$ & 0 & 0 & 8 & 13 & 76 & 3,62 & ,498 \\
\hline & & & & & Total & 17,90 & 2,824 \\
\hline & & & & & $\begin{array}{l}\text { Rata - } \\
\text { rata }\end{array}$ & 2,98 & 0,471 \\
\hline & & & & & Kategori & Baik & \\
\hline
\end{tabular}

Dari tabel 17 dapat diketahui sebagai berikut:

a. Item pernyataan kepuasan apoteker 1, diperoleh jumlah dan persentase jawaban dari 21 responden yang telah mengisi kuesioner adalah sebanyak 18 (85,71\%) responden yang menyatakan setuju dan sebanyak $3(14,29)$ responden menyatakan sangat setuju. Hal ini berarti apoteker setuju dengan pernyataan bahwa BPJS dalam melayani FKTP belum/tidak memuaskan. Sesuai kenyataan apoteker di FKTP di Kabupaten Jombang dan Madiun sebagian besar merasa belum puas dengan pelayanan BPJS Kesehatan secara keseluruhan terutama dalam bidang kefarmasian.

b. Item pernyataan kepuasan apoteker 2 , diperoleh jumlah dan persentase jawaban dari 21 responden yang telah mengisi kuesioner adalah sebanyak 14 (66,67\%) responden yang menyatakan sangat setuju. Hal ini berarti apoteker di FKTP Kabupaten Jombang dan Madiun sebagian besar setuju jika BPJS mendorong 
FKTP untuk bekerjasama. Para apoteker di FKTP merasa terdapat beberapa keuntungan dengan bekerja sama dengan BPJS. Misalkan apoteker di puskesmas mendapat jasa pelayanan dari biaya klaim pasien BPJS, apoteker di apotek jejaring dapat menambah income apotek dengan banyaknya resep pasien Program Rujuk Balik BPJS.

Dari hasil tersebut apoteker menilai baik sehingga dapat dikatakan apoteker di FKTP Kabupaten Jombang dan Madiun sebagian besar merasa puas dengan pelayanan BPJS secara keseluruhan terutama dalam bidang kefarmasian seperti sistem pengadaan obat. Adanya informasi call center dan kantor cabang BPJS di setiap daerah dapat memberikan kemudahan tentang kejelasan informasi maupun penyampaian keluhan kepada BPJS.

\section{Analisis Data dan Uji Hipotesis}

Analisis regresi linier sederhana, hasil analisis regresi linier sederhana dapat dilihat pada tabel sebagai berikut:

Tabel 6. Hasil analisis regresi linier sederhana

\begin{tabular}{cccc}
\hline Variabel & $\begin{array}{c}\text { Pearson } \\
\text { Correlation }\end{array}$ & $P$ value & $\mathrm{N}$ (jumlah) \\
\hline Pengadaan obat & 0,835 & 0,000 & 21 \\
\hline Sumber: data primer yang diolah, 2015 & &
\end{tabular}

Hasil analisis regresi linier dapat diketahui tingkat hubungannya dengan melihat tabel 18 yaitu interpretasi koefisien korelasi sebagai berikut :

1) Antara pengadaan obat dengan kepuasan apoteker koefisien korelasinya menunjukkan angka 0,835 yang terletak pada interval 0,799-1,00 berarti tingkat hubungannya sangat kuat. Artinya pada variabel pengadaan obat dikatakan sangat kuat dalam memperngaruhi kepuasan apoteker di FKTP terhadap pelayanan BPJS. Dengan $p$ value 0,000 yang berarti pengadaan obat berpengaruh signifikan terhadap kepuasan apoteker.

2) Nilai t hitung dari pengadaan obat adalah sebesar 3,849 dengan signifikansi 0,000 berarti variabel bebas pengadaan obat berpengaruh secara signifikan terhadap kepuasan apoteker.

\section{Kesimpulan}

Berdasarkan hasil analisis data penelitian tentang analisis pengaruh pelayanan BPJS terhadap kepuasan apoteker di Fasilitas Kesehatan Tingkat I Kabupaten Jombang dan Madiun didapatkan kesimpulan bahwa Pengadaan obat berpengaruh secara signifikan terhadap kepuasan apoteker di FKTP.

\section{Daftar Pustaka}

Abdurrahman, D. M. (2003). Pendidikan bagi Anak berkesulitas belajar. PT. Asdi Mahastya.

Hadidah, I. S. (2016). Faktor Penyebab Kejadian Stagnant Dan Stockout Di Instalasi Farmasi Upt Rumah Sakit Mata Masyarakat Jawa Timur. Jurnal Manajemen $\begin{array}{lllll}\text { Kesehatan Yayasan } & \text { RS.Dr. Soetomo, } & 110 .\end{array}$ https://doi.org/10.29241/jmk.v2i2.56

Menteri kesehatan RI. (2008). Lampiran Keputusan Menteri Kesehatan Nomor 1121/Menkes/SK/XII/2008 tentang Pedoman Teknis Pengadaan Obat Publik Dan Perbekalan Kesehatan Untuk Pelayanan Kesehatan Dasar. 
https://www.researchgate.net/publication/269630909

Menteri kesehatan RI. (2011). Peraturan Menteri Kesehatan Republik Indoensia Nomor 028/ Menkes/ Per/l/2011 tentang Klinik.

Menteri kesehatan RI. (2014). Peraturan Menteri Kesehatan Republik Indonesia Nomor 63 Tahun 2014 tentang Pengadaan Obat Berdasarkan Katalog Elektronik (Ecatalogue).

Menteri Kesehatan RI. (2014). Peraturan Menteri Kesehatan Republik Indonesia Nomor 28 Tahun 2014 tentang Pedoman Pelaksanaan Program Jaminan Kesehatan Nasional (Vol. http://dx.doi.org/10.1016/j.respol.2011.09.003\%0Ahttps://doi.org/10.1016/j.worldde v.2020.104995\%0Ahttp://dx.doi.org/10.1016/j.worlddev.2009.12.011\%0Ahttp://pub licaciones.eafit.edu.co/index.php/ecoseconomia/article/view/1969/1978\%0Ahttps://doi.org/10.1016

Pemerintah RI. (2004). Undang-Undang Republik Indonesia Nomor 40 Tahun 2004 tentang Sistem Jaminan Sosial Nasional.

Prabowo, P. (2016). Analisis Faktor-Faktor yang Mempengaruhi Ketersediaan Obat di Era JKN pada RSUD dr. Soedono Madiun 1. 1-11.

Priyatno, D. (2010). Duwi Priyatno, 2010. Teknik Mudah dan Cepat Melakukan Analisis Data Penelitian dengan SPSS dan Tanya Jawab Ujian Pendadaran. Gaya Media, Yogyakarta.

Rahmah, F. (2018). Perencanaan dan Pengadaan Obat di Puskesmas " $X$ " Berdasarkan Permenkes Nomor 74 Tahun 2016. Jurnal Administrasi Kesehatan Indonesia, 6(1), 15. https://doi.org/10.20473/jaki.v6i1.2018.15-20

Rosmania, F. A. (2015). Analisis pengelolaan Obat Sebagai Dasar Pengendalian Safety Stock Pada Stagnant dan Stockout Obat _. Ekp, 13(3), 1-10.

Sudjana, N. (2004). Dasar-Dasar Proses belajar Mengajar. PT. Sinar Baru Algensido Offsite.

Sugiono. (2009). Metodologi Penelitian Kualitatif dan R\&D. Alfabeta.

Pharmed Vol. 3, No. 2, Agustus 2020: 73 - 84 